\title{
$\sqrt{12}$ \\ P R I F Y S G O L \\ B A N G OR \\ U N I VERS I T Y
}

\section{Resilience of tropical dry forests - a meta-analysis of changes in species diversity and composition during secondary succession}

Derroire, G.; Balvanera, P.; Castellanos-Castro, C.; Decocq, G.; Kennard, D.K.; Lebrija-Trejos, E.; Leiva, J.A.; Oden, P.; Powers, J.S.; Rico-Gray, V.; Tigabu, M.; Healey, J.R.

\section{Oikos}

DOI:

10.1111/oik.03229

Published: 01/10/2016

Peer reviewed version

Cyswllt i'r cyhoeddiad / Link to publication

Dyfyniad o'r fersiwn a gyhoeddwyd / Citation for published version (APA):

Derroire, G., Balvanera, P., Castellanos-Castro, C., Decocq, G., Kennard, D. K., Lebrija-Trejos, E., Leiva, J. A., Oden, P., Powers, J. S., Rico-Gray, V., Tigabu, M., \& Healey, J. R. (2016). Resilience of tropical dry forests - a meta-analysis of changes in species diversity and composition during secondary succession. Oikos, 125(10), 1386-1397.

https://doi.org/10.1111/oik.03229

\footnotetext{
Hawliau Cyffredinol / General rights

Copyright and moral rights for the publications made accessible in the public portal are retained by the authors and/or other copyright owners and it is a condition of accessing publications that users recognise and abide by the legal requirements associated with these rights.

- Users may download and print one copy of any publication from the public portal for the purpose of private study or research.

- You may not further distribute the material or use it for any profit-making activity or commercial gain

- You may freely distribute the URL identifying the publication in the public portal ?
}

Take down policy

If you believe that this document breaches copyright please contact us providing details, and we will remove access to the work immediately and investigate your claim. 


\section{Resilience of tropical dry forests - a meta-analysis of changes in species diversity}

and composition during secondary succession

Géraldine Derroire $^{1}$, Patricia Balvanera ${ }^{3}$, Carolina Castellanos-Castro ${ }^{4}$, Guillaume Decocq $^{2,5}$, Deborah K. Kennard ${ }^{6}$, Edwin Lebrija-Trejos ${ }^{7}$, Jorge A. Leiva ${ }^{8}$, Per-Christer

Odén $^{2}$, Jennifer S. Powers ${ }^{9,10}$, Victor Rico-Gray ${ }^{11}$, Mulualem Tigabu ${ }^{2}$ and John R. Healey ${ }^{1}$

${ }^{1}$ School of Environment, Natural Resources and Geography, Bangor University, Deiniol Road, Bangor, Gwynedd, LL57 2UW, UK

${ }^{2}$ Southern Swedish Forest Research Centre, Swedish Univ. of Agriculture Sciences, Alnarp, Sweden

${ }^{3}$ Inst. de Investigaciones en Ecosistemas y Sustentabilidad, Univ. Nacional Autonoma de Mexico, Morelia, Michoacan, Mexico

${ }^{4}$ Inst. de Investigación de Recursos Biológicos Alexander von Humboldt, Bogotá D.C., Colombia

${ }^{5}$ UR "Ecologie et Dynamique des Systèmes Anthropisés" (EDYSAN, FRE 3498 CNRSUPJV), Jules Verne Univ. of Picardie, Amiens, France

${ }^{6}$ Dept of Physical and Environmental Sciences, Colorado Mesa University, Grand Junction, CO, USA

${ }^{7}$ Dept of Biology and Environment, Faculty of Natural Sciences, Univ. of Haifa Oranim, Tivon, Israel

${ }^{8}$ Soil and Water Science Dept, Univ. of Florida, Gainesville, FL, USA

${ }^{9}$ Dept of Ecology, Univ. of Minnesota, Saint Paul, MN, USA

${ }^{10}$ Dept of Plant Biology, Univ. of Minnesota, Saint Paul, MN, USA.

${ }^{11}$ Inst. de Neuroetología, Univ. Veracruzana, Xalapa, Veracruz, México

Corresponding author: G. Derroire, School of Environment, Natural Resources and Geography, Bangor University, Deiniol Road, Bangor, Gwynedd, LL57 2UW, UK. Email: g.derroire@bangor.ac.uk

Decision date: 11-Mar-2016

This article has been accepted for publication and undergone full peer review but has not been through the copyediting, typesetting, pagination and proofreading process, which may lead to differences between this version and the Version of Record. Please cite this article as doi: [10.1111/oik.03229]. 


\section{(Abstract)}

Assessing the recovery of species diversity and composition after major disturbance is key to understanding the resilience of tropical forests through successional processes, and its importance for biodiversity conservation. Despite the specific abiotic environment and ecological processes of tropical dry forests, secondary succession has received less attention in this biome than others and changes in species diversity and composition have never been synthesised in a systematic and quantitative review. This study aims to assess in tropical dry forests 1) the directionality of change in species richness and evenness during secondary succession, 2) the convergence of species composition towards that of old-growth forest and 3) the importance of the previous land use, precipitation regime and water availability in influencing the direction and rate of change. We conducted meta-analyses of the rate of change in species richness, evenness and composition indices with succession in 13 tropical dry forest chronosequences. Species richness increased with succession, showing a gradual accumulation of species, as did Shannon evenness index. The similarity in species composition of successional forests with old-growth forests increased with succession, yet at a low rate. Tropical dry forests therefore do show resilience of species composition but it may never reach that of old-growth forests. We found no significant differences in rates of change between different previous land uses, precipitation regimes or water availability. Our results show high resilience of tropical dry forests in term of species richness but a slow recovery of species composition. They highlight the need for further research on secondary succession in this biome and better understanding of impacts of previous land-use and landscape-scale patterns. 


\section{Introduction}

Succession has been a major focus of plant community ecology for more than a century (McIntosh 1999), yet the processes underlying assembly of secondary forests continue to be actively researched (Norden et al. 2015). The early view of Clements (1916) (monoclimax hypothesis) and initial floristic composition model of Egler (1954) were further formalized by the three models of Connell and Slatyer (1977). These deterministic models are all based on the idea that trade-offs between traits promote success in different stages of succession (Huston and Smith 1987). However, none of these models accounts for stochastic events or historical contingencies (Young et al. 2005). Lawton (1987) proposed a model of succession based only on random survival of established species and colonization by new species, paving the way for the neutral theory of community assembly (Hubbell 2001). Although deterministic niche-based and neutral models of succession have often been treated as mutually exclusive explanations for empirical patterns, a growing body of literature evidences the importance of the integration of the two (Chave 2004, Gravel et al. 2006, Tilman 2004). A major focus of research is now to assess the resilience of forests and the factors affecting it (Arroyo-Rodriguez et al. 2016, Norden et al. 2009). Resilience is defined here as the capacity and rate of recovery of the structure, composition and functioning that the forest had before disturbance (Chazdon and Arroyo 2013, Newton and Cantarello 2015). Niche-based deterministic processes promote a gradual return of the species previously present in old-growth forest and therefore lead to a good recovery of species composition, while neutral processes lead to more idiosyncratic trajectories of succession (Norden et al. 2009).

Complex interactions between intrinsic and extrinsic factors (Finegan 1984, Lebrija-Trejos et al. 2010) affect successional trajectories and therefore the resilience of forests. Within a given site, abiotic conditions (e.g. soil and climatic factors) affect plant regeneration. The nature and intensity of past land uses and current disturbances can lead to different rates of recovery of species composition (Kennard et al. 2002, Molina Colon and Lugo 2006). Remnant trees in abandoned pastures foster the establishment of young woody plants under their crown and influence the composition of these new plant assemblages (Derroire et al. 2016, Guevara et al. 1986). At the larger scale of the landscape, remnant forests provide seeds that can be dispersed to adjacent successional forests (Chazdon 2014).

In the tropics, most studies of succession have been carried out in moist and wet forests. The resulting models are however not applicable to tropical dry forests (TDF) where there are different ecological processes and changes in functional composition with succession (Lohbeck et al. 2013, Quesada et al. 2009). In TDF, seasonal water limitations strongly determine ecological processes (Maass

'This article is protected by copyright. All rights reserved.' 
and Burgos 2011) while tropical wet forests are more limited by light availability and biotic interactions (Ewel 1977). Regeneration in TDF is characterized by the importance of vegetative reproduction, which can improve recovery of woody vegetation through resprouting, and by the high proportion of anemochorous species whose seeds can better colonise early successional sites (Vieira and Scariot 2006). During TDF succession, there is an extensive change in environmental conditions from hot and waterlimited early stages towards more shaded later stages (Lebrija-Trejos et al. 2011), suggesting an important role of facilitative biotic interactions (Callaway and Walker 1997, Derroire et al. 2016). However, the strength of the light gradient is lower in TDF than in wet forests due to smaller differences in light conditions between the early and late stages of succession (Ewel 1977, Letcher et al. 2015), suggesting a faster recovery of old-growth forest species. Furthermore, difference in precipitation regimes among TDF can affect successional processes. Becknell et al. (2012) synthesized the structural changes occurring during succession in TDF and showed that wetter sites reach a greater biomass than drier ones, suggesting steeper environmental gradients between early and late succession in wetter sites. McDonald et al. (2010) showed that the relative importance of resprouting and regeneration by seed changed with precipitation regimes, with resprouting being more important in drier sites. Derroire et al. (2016) showed evidence that facilitation is more important in drier sites. These differences all suggest more differentiation between the species composition of early and late successional communities in TDF where precipitation is higher, in line with the findings of Letcher et al. (2015) that successional habitat specialisation is stronger for tropical wet forests than TDF.

Here we used meta-analysis of 13 chronosequences to assess the resilience capacity of TDF and the factors influencing it. The changes in biomass during succession have been quantitatively reviewed by Becknell et al. (2012) in TDF, Poorter et al. (2016) across Neotropical forests and Martin et al. (2013) across tropical forests. Martin et al. (2013) also reviewed changes in species richness and composition across tropical forests. Here we provide a new focus on the changes in species diversity (richness and evenness) and composition during secondary succession in TDF. We asked the following questions: (1) Do species richness and evenness change in a directional way with succession and what are the direction and rate of change? If there are strong limitations to dispersal or if species arriving early in succession inhibit the arrival of other species, we expect limited or no changes in species richness, at least in the earlier stages. (2) How convergent are the changes in species composition with succession? In other words, does the composition of successional forests converge towards the composition of old-growth forests, indicating resilience, and how fast? Niche-based assembly should lead to an increasing

'This article is protected by copyright. All rights reserved.' 
compositional similarity between successional forests and old-growth forests, as environmental conditions change towards those of old-growth forests. On the other hand, inhibition of new species arrival by the early established vegetation would impede the increase in similarity. (3) Do the previous land use, precipitation regime and water availability affect the directionality and rate of change in species richness, evenness and composition during succession? We expect a difference between pasture and shifting cultivation land uses in their influence on subsequent succession because of their effects on the soil and remnant vegetation. Moreover, we expect the precipitation regime and water availability to influence the rates of change. The greater importance of resprouting and facilitation in drier forests predicts a faster accumulation of species. However, the greater range of environmental conditions and species successional habitat specialisation in wetter forests predicts a greater rate of change in species composition.

\section{Methods}

We have chosen a meta-analysis approach because it is a powerful and unbiased method to combine study results across multiple sites and test the effect of factors that are difficult to test with primary data (Koricheva and Gurevitch 2013), in our case previous land use, precipitation regime and water availability. Our methods follow the guidelines of Koricheva and Gurevitch (2014) and Woodcock et al. (2014) on methodology and reporting of systematic reviews and meta-analyses.

\section{Data search and inclusion criteria}

We searched Web of Science, Science Direct and JSTOR for studies of the composition of TDF during succession in April 2012. We used the following search string: (succession* OR secondary) AND tropical AND dry AND forest*. We complemented this search by screening the references cited by the publications we found, by searching books on TDF and asking colleagues for grey literature. We updated this search in June 2015 using Web of Science and Science Direct and the initial search string. A broader literature search on TDF found no additional relevant publications.

We used the following inclusion criteria to select relevant studies: (1) they considered TDF, defined as forests with a mean annual precipitation (MAP) between 500 and $2000 \mathrm{~mm}$ and mean annual temperature above $17^{\circ} \mathrm{C}$ (Becknell et al. 2012, Holdridge 1967) with at least three months of drought (precipitation <100 mm) (Sanchez-Azofeifa et al. 2005). (2) They studied natural succession. We excluded studies of forests where an active human intervention was conducted, such as restoration planting or fertilisation (e.g. Souza and Batista (2004)). (3) They conducted an inventory of trees and

'This article is protected by copyright. All rights reserved.' 
shrubs in plots of different successional age (i.e. time since abandonment of the previous land use). They focused on adults, rather than on the soil seed bank, seedlings or saplings (e.g. Maza-Villalobos et al. (2011)). (4) They provided information on previous land use. (5) They reported data from plots with at least three different values of successional age (to enable fitting of linear regression with successional age), using either a dynamic or a chronosequence approach. For the chronosequence approach, we checked that within datasets, plots were located on sites with the same climate, similar previous land use and no substantial known soil differences. We excluded studies with a different sampling design between the different successional ages (e.g. Larkin et al. (2012)). (6) The youngest age of plots within a study was not more than 10 years, because case studies in TDF (Lebrija-Trejos et al. 2010) and global syntheses (Martin et al. 2013, Poorter et al. 2016) have shown rapid changes in the early stages of succession that we wanted to be able to assess across studies. (7) Because we calculated selected indices in order to assure comparability of studies, we needed raw data in the form of a floristic table of abundance of each species in each plot (not just aggregated data per successional age). Studies measuring only species occurrence or cover-abundance (e.g. Kassi N'Dja and Decocq (2008)) were not considered. The inclusion of a study was ultimately dependent on the agreement of authors to provide raw data.

\section{Data preparation and exploration}

Some selected studies included sets of plots (referred to as "datasets") with different previous land uses, soil and/or vegetation types, with each of the datasets independently meeting the inclusion criteria. These datasets were considered as independent units in our meta-analyses.

Some datasets focused only on dicot trees and shrubs while others also considered palms, lianas, cacti and herbs. To remove this possible source of difference between datasets, we excluded life forms other than dicot trees and shrubs from all the floristic tables. Plots with missing information (e.g.

successional age, previous land use) or with no trees or shrubs were also removed from the datasets.

Some studies used nested subplots of different sizes within each plot for different tree size categories, with a coherent design for all successional ages. In these cases, the number of individuals of each species per subplot was scaled to the size of the plot, using the method of Lebrija-Trejos et al. (2010) and values per size category summed. When the raw data gave the size or size class of individual stems, we excluded stems below the range of minimum diameters that we imposed to maximise consistency across the studies (Table 1).

For each plot in every dataset, we calculated the species richness and Shannon evenness index. To account for the differences in number of stems between plots, within and across datasets, we 'This article is protected by copyright. All rights reserved.' 
standardised species richness to a fixed number of stems (15), following the method proposed by Colwell et al. (2012). We selected the number 15 to avoid standardising to more than three times the actual number of stems (the limit recommended by Colwell et al. (2012)) for 98.5\% of the plots. Standardised Shannon and Simpson diversity indices, which combine richness and evenness (Magurran 2005), were also calculated but their meta-analyses gave qualitatively similar results to those for species richness so we do not present these results. To investigate the compositional similarity between successional plots and old-growth reference plots in the same dataset, we calculated the Sørensen index (based on species occurrence) and the version of the Chao-Sørensen index (based on species abundance) that is not adjusted for missing species. For any pair of successional and old-growth plots, the Sørensen index is $2 \mathrm{~S}_{12} /\left(\mathrm{S}_{1}+\mathrm{S}_{2}\right)$ where $S_{12}$ is the number of shared species, $S_{1}$ is the number of species in the successional plot and $S_{2}$ in the old-growth plot, and the Chao-Sørensen index is $2 \mathrm{UV} /(\mathrm{U}+\mathrm{V})$ where $\mathrm{U}$ is the total relative abundance of the shared species in the successional plot, and V in the old-growth plot (Chao et al. 2005). These two indices differ in giving more (Sørensen) or less (Chao-Sørensen) relative weight to rare species. When several old-growth plots were available within a dataset, the similarity indices were calculated separately for each plot and averaged. Calculations were performed using the packages VEGAN (Oksanen et al. 2015) and iNEXT (Hsieh et al. 2015) in R 3.2.3 (R core team 2015). When the successional age was provided as a range, we used the midpoint of the range. For each dataset, relationships between successional age and each index were visually explored by fitting local polynomial regressions (function LOESS in R)

(Cleveland et al. 1992) (Supplementary material Appendix 1 Fig. A1) to get a preliminary understanding of the trends observed for each dataset.

To investigate the source of heterogeneity between datasets, we retrieved values for the following variables from the publications or asked the authors when necessary: previous land use, mean annual precipitation (MAP), number of dry months (precipitation $<100 \mathrm{~mm}$ ) and duration of succession studied (defined as age of the oldest successional plot). Climatic data were checked with online data provided by local meteorological institutes. We also calculated the ratio of annual Potential Evapotranspiration to MAP (PET/MAP) as a measure of water availability, using PET data computed with the FAO Penman - Monteith method for the period 1961-1990 (downloaded from http://www.fao.org/geonetwork/srv/en/ on 24 January 2016). We used information on soil taxonomy provided in each publication to categorise the datasets into two soil fertility groups, low and high. In brief, we assumed that highly weathered soils described as ultisols or oxisols (ferrosols) were depleted in nutrients, and geologically younger soils, including entisols, inceptisols, alfisols and/or mollisols, had

'This article is protected by copyright. All rights reserved.' 
higher fertility. The surrounding landscape is also very likely to influence the process of succession but the absence of sufficient information in the reviewed studies did not allow this to be tested.

Our search and selection gave thirteen datasets from nine studies published between 1992 and 2015, all using a chronosequence approach. Table 1 lists the datasets and provides information on the environment and study design, as well as the number of datasets included in each meta-analysis. Six datasets provided data on both successional and old-growth forests, allowing calculation of the indices of similarity between successional stages and old-growth forests. The number of plots per dataset, excluding old-growth references, ranged from 4 to 290 (median 19). Plot area ranged from 100 to $1000 \mathrm{~m}^{2}$ (median 500). The minimum Diameter at Breast Height (DBH) for inclusion of trees and shrubs ranged from 1 to $10 \mathrm{~cm}$ (median 2.5). Six datasets covered a duration of succession $\leq 30$ years and seven $>30$ years (maximum 60 years). The previous land uses were pasture (8 datasets) and shifting cultivation (5 datasets). MAP ranged from 788 to $1647 \mathrm{~mm}$ (median $1129 \mathrm{~mm}$ ), the number of dry months from 5 to 7.5 (median 5.5) and the ratio PET/MAP from 0.831 to 1.999 (median 1.507). The soil fertility was high for 11 of the 12 datasets for which we had data, so we did not use this variable in the meta-analyses. Most of the datasets were collected in North and Central America (five from Costa Rica and three from Mexico). Four datasets were from South America (three from Colombia and one from Bolivia) and one from Asia (Laos).

\section{Meta-analyses}

We performed meta-analysis for each index of species richness, evenness and compositional similarity, using the METAFOR package (Viechtbauer 2010) in R 3.2.3 ( $\mathrm{R}$ core team 2015). The effect size (response variable of the meta-analysis) was the estimate of the slope of the linear regression of the considered index against successional age, calculated for each dataset (Rosenberg et al. 2013). Meta-analyses are therefore fitted on a maximum of 13 datasets (Table 1). Successional trends showed various shapes (Supplementary material Appendix 1 Fig. A1), yet linear relationships provided a good approximation across datasets. Their slopes are an effect size that can be analysed by a meta-analysis approach to show the directionality and rate of trends across datasets. Assumptions of normality of residuals and homogeneity of variance of the linear regressions were met (checked graphically). The effect sizes and associated variances, and the goodness of fit $\left(\mathrm{R}^{2}\right)$, for each index and dataset are presented in Supplementary material (Appendix 2 Fig. A2 and Appendix 3 Table A3 respectively).

We first fitted meta-analyses using random-effect models to account for heterogeneity between datasets due to ecological and methodological differences (random models include a dataset-specific

'This article is protected by copyright. All rights reserved.' 
variation) (Mengersen et al. 2013). Second, to investigate reasons for heterogeneity between datasets, we fitted meta-regressions, a type of meta-analysis using moderators (i.e. fixed factors: previous land use, MAP, number of dry months, PET/MAP and duration of succession studied in the dataset) to explain the differences among datasets (Mengersen et al. 2013). Meta-regressions were fitted with mixed-effect models to account for heterogeneity between datasets. Ideally, all moderators would be included in a single model but we had to fit separate models for each moderator to avoid over-fitting due to the small number of available datasets. Duration of succession studied was considered as a categorical variable with two values ( $\leq$ or $>30$ years) because we observed an inflection of the nonlinear relationships between indices and successional age around that age for several studies (Supplementary material Appendix 1 Fig. A1). Meta-analysis and meta-regression models were fitted using the restricted maximum likelihood (REML) estimation method. Datasets were weighted by the inverse of the variance of the estimate of the slope of the linear regression to account for statistical precision of the effect size of each datasets (Koricheva and Gurevitch 2013). Heterogeneity between datasets was tested with the Cochran Q test for meta-analyses and Q-E test for meta-regressions (Cochran 1954).

We used two methods to test for publication bias and robustness of the significant results: graphical observation of funnel plots (Light and Pillemer 1984) and fail-safe number (Rosenberg 2005). In brief, a funnel plot is a plot of the effect size of each dataset against a measure of its variance (here standard error). In the absence of publication bias the plot has a funnel shape symmetric around the mean effect, because the variability and range of effect sizes decreases with decreasing standard error (Jennions et al. 2013). The fail-safe number is the number of datasets with null effect that need to be added to lose the significance of the estimated effect size (at $p=0.05$ ). Results are considered robust if the fail-safe number is greater than $5 \mathrm{~N}+10, \mathrm{~N}$ being the number of datasets included in the analysis for the considered moderator (Rosenthal 1979).

\section{Results}

\section{Species richness and evenness indices}

Overall, the species richness and Shannon evenness indices had positive effect sizes, meaning that they increased with succession (Fig. 1, Supplementary material Appendix 4 Table A4), however, the trend observed for Shannon evenness index was not observed when using Simpson evenness index (data not shown). For both indices, the effect sizes were higher for sites previously used as pasture than for shifting cultivation (for the latter they were not significantly different from 0), although the difference between

'This article is protected by copyright. All rights reserved.' 
them was significant for Shannon evenness index $(\mathrm{p}=0.003)$ but not for species richness $(\mathrm{p}=0.108)$. Contrary to expectation, effect sizes were not significantly correlated with the MAP, the number of dry months or PET/MAP (Supplementary material Appendices 4 Table A4 and 5 Fig. A5), indicating that the rate of change in species richness and evenness indices with succession was not significantly dependent on precipitation regime or water availability. For Shannon evenness index, datasets with a duration of succession studied > 30 years showed a significantly higher effect size than shorter-term datasets (for which the effect size was not significantly different from zero), suggesting that evenness increases faster in the later stages of succession. However, there was no significant effect of the studied duration of succession for species richness. For the two indices, the Cochran Q and Q-E tests showed a high heterogeneity between all datasets and also between datasets with the same previous land use or duration of succession studied (Fig. 1). Funnels plots did not reveal publication bias for any of the meta-analyses (Supplementary material Appendix 6 Fig. A6) and the fail-safe numbers showed good robustness for all significant effect sizes (Fig. 1), except for the effect size of species richness calculated for data sets with a studied duration of succession $\leq 30$ years.

\section{Similarity with old-growth forest}

Overall, the effect size of both the Sørensen and Chao-Sørensen indices were positive and quite similar (0.008 and 0.009 respectively) but not significant $(\mathrm{p}=0.075$ and $\mathrm{p}=0.143$ respectively) (Fig. 2 ,

Supplementary material Appendix 4 Table A4). For both indices, the effect sizes differed between the two classes of duration of succession studied. For the five datasets $>30$ years the effect sizes were significantly positive ( 0.003 for both indices) and the fail-safe number showed that these results were very robust, indicating that similarity of composition with old-growth forests increases with succession for the longer-duration datasets. For the dataset $\leq 30$ years, the effect sizes were also significantly positive

for both indices but not robust, probably because there was only a single dataset. The effect sizes were not significantly dependent on previous land use (Fig. 2), MAP, number of dry months or PET/MAP (Supplementary material Appendices 4 Table A4 and 5 Fig. A5). For both indices, there was a high heterogeneity between datasets (Fig. 2), overall and between datasets with the same previous land use and same category of duration of succession studied. Funnels plots did not reveal publication bias for the significant results (Supplementary material Appendix 6 Fig. A6).

\section{Discussion}

\section{Gradual accumulation of species}

'This article is protected by copyright. All rights reserved.' 
The gradual increase in species richness revealed by our meta-analysis is in line with the trends generally observed in tropical dry and wet forests (Chazdon et al. 2007, Dent et al. 2013, Lebrija-Trejos et al. 2008, Letcher and Chazdon 2009, Quesada et al. 2009). This shows a gradual colonisation and establishment of tree species during succession (Anderson 2007, Chazdon et al. 2007). For the datasets including old-growth forests, species richness in the plots of greater successional age is close to that of old-growth forests (Supplementary material Appendix 1 fig. A1). This is consistent with the findings of Martin et al. (2013) who estimated that tropical forests can recover their species richness in about 50 years. This supports the suggestion that seed availability is not a major limitation to species colonisation in the considered forests (Lebrija-Trejos et al. 2008, Vieira and Scariot 2006), which can have two nonmutually exclusive explanations: (1) TDF have a high proportion of anemochorous species (Bullock 1995), the dispersal of which is less affected by forest fragmentation (Janzen 2002). (2) The mosaic of secondary forests, old-growth forests and agricultural land with scattered trees described by most studies (e.g. Kennard (2002)), which is a notable characteristic of Neotropical dry landscapes (Chazdon et al. 2011), seems to ensure a relatively high availability and dispersal of seeds to successional forests (Chazdon 2014). However, it is likely that large-seeded species requiring specialist dispersers may arrive only in the late stages of succession (Chazdon 2014, Lohbeck et al. 2013).

We found no significant effect of the duration of succession studied on the rate of increase in species richness (Fig. 1a). For several datasets, the relationship is quite linear (Kennard (2002), LebrijaTrejos et al. (2008), Leiva et al. (2009), Mora et al. (2015), Powers et al. (2009) Palo Verde and Santa Rosa oak). A study of the successional dynamics (Lebrija-Trejos et al. 2010) in one of the included datasets (Lebrija-Trejos et al. 2008) showed that the accumulation of old-growth forest species occurs at a faster rate than the loss of early successional species, explaining the increase in species richness even in the later stages. This trend can also be explained by the generalist species, able to establish throughout succession and then persist. Rozendaal and Chazdon (2015) found that such species were abundant in successional tropical wet forests, which is also likely to be the case in TDF where the environmental gradient during succession is less strong (Letcher et al. 2015).

We found an overall increase of Shannon evenness index with succession, and the rate of increase was higher where the previous land use was pasture and for longer duration datasets (Fig. 1). This increase is consistent with observations from tropical wet and dry forests (Capers et al. 2005, Ruiz et al. 2005, Saldarriaga et al. 1988). However, despite the importance of evenness in explanations for the maintenance of species richness in tropical forests (Connell 1978), changes in species evenness with 'This article is protected by copyright. All rights reserved.' 
succession are poorly explained. Biotic interactions (competition and facilitation) are likely to drive patterns of evenness because of their effect on species relative abundance, however further evidence is required from studies focused on changes in individual species, and ultimately on the interactions between species.

\section{Convergence toward old-growth forest species composition}

The similarity of species composition with old-growth forests increased with succession, as indicated by both the Sørensen and Chao-Sørensen indices when the two classes of duration of succession studied were considered separately (Fig. 2). This is also the trend observed for individual datasets (Supplementary material Appendix 1 Fig. A1, Appendix 2 Fig. A2). There is a convergence toward the composition of old-growth forests, supporting a directional trajectory of succession in TDF. However, the increases of both Sørensen and Chao-Sørensen indices with successional age were slow, and for all datasets the similarity of successional plots with old-growth plots remained low even for the later stages of succession (Supplementary material Appendix 1 Fig. A1). This shows an important uncertainty in the recovery of species composition during succession, as also found by Martin et al. (2013) across tropical forests. The arrival of a given species depends on stochastic events and on the availability of seeds from the surrounding landscape. As a consequence, successional trajectories can be better predicted by considering functional groups rather than species composition, as found in TDF and tropical moist forests (Dent et al. 2013, Lebrija-Trejos et al. 2010). Our results suggest that the recovery of the full species composition of old-growth forests may never occur before the next major disturbance event (Chazdon 2008, Chazdon et al. 2007).

The rate of convergence in species composition is similar when calculated with species occurrence (Sørensen index) and with species abundance (Chao-Sørensen) (Fig. 2), suggesting that there is no notable difference in the rate of establishment of abundant and rare species. This result is surprising: because species that are abundant in old-growth forest are more likely to be abundant in the seed rain, we would have expected the species that are abundant in old-growth forests to establish and reach a high level of abundance during succession faster than rarer species. This finding may be attributable to the high evenness observed for most of the datasets (Supplementary material Appendix 1 Fig. A1).

For both indices, the rate of convergence is much higher for the shorter-duration datasets $(\leq 30$ years) than for the longer-term datasets, suggesting that the arrival of species present in old-growth forests is important in the early stages of succession. This is in line with the results of Lebrija-Trejos et al. (2010) and Chazdon et al. (2011) (obtained using the same data as Lebrija-Trejos et al. (2008) and Mora

'This article is protected by copyright. All rights reserved.' 
et al. (2015) respectively) who observed recruitment of old-growth forest species from the early stages of succession. This is probably due to the rapid recovery of the structure of TDF: Lebrija-Trejos et al. (2008) found that canopy height, plant density and crown cover recovered in less than 15 years in a Mexican TDF and Becknell et al. (2012) showed that above-ground biomass reached its maximum in 30 to 50 years. These rapid structural changes provide suitable micro-environmental conditions (increased shading and decreased temperature) for the establishment of species associated with later stages of succession (Chazdon et al. 2011, Lebrija-Trejos et al. 2010). This is consistent with the study of Letcher et al. (2015) showing a lower rate of habitat specialisation of species in TDF than in wet forests, allowing old-growth forest species to arrive earlier in succession. However, this result could also be an artefact of only one study being analysed for the shorter-duration class, and it needs to be retested once a greater number of studies become available.

\section{Factors affecting the rate of change}

We found a high heterogeneity amongst studies in the rates of change in species richness, evenness and composition with successional age (Fig. 1, Fig. 2), confirming that time is not the only factor controlling changes during succession. Successional pathways result from a number of interacting factors (Chazdon 2014) that we discuss below.

Our results only showed a significant difference in the direction and rate of change between the two previous land uses, pasture and shifting cultivation, for Shannon evenness (Fig. 1, Fig. 2). For species richness, the rate of change was higher in pasture but the difference between the two land uses was not significant $(\mathrm{p}=0.108)$. The latter result is consistent with those of Norden et al. (2015) and Poorter et al. (2016), and can be explained by the complexity of the effects of previous and on-going land uses. (1)

Cultivation can lead to greater soil erosion (Maass et al. 1988) impeding forest recovery. (2) The presence of remnant trees, reported by all datasets of sites previously under pasture, can affect long-term successional trajectories (Sandor and Chazdon 2014, Schlawin and Zahawi 2008) by their capacity to resprout (Sampaio 2007, Vieira et al. 2006), attract seed dispersers (Guevara et al. 1986) and provide suitable conditions for woody species establishment (Derroire et al. 2016, Duarte et al. 2010). (3) The intensity and duration of the previous land use are important (Pereira et al. 2003). For sites previously used for shifting cultivation, the number of cultivation cycles can affect successional trends (Sovu et al. 2009). Moreover, several land uses may have occurred before abandonment. For example, the combination of cultivation and grazing is common in shifting cultivation practices in Mexico (Chazdon et al. 2011, Morales-Barquero et al. 2015). (4) Perturbation after abandonment of agriculture can also affect 'This article is protected by copyright. All rights reserved.' 
the composition of successional forests. Powers et al. (2009) suggest that the abundance of the cattledispersed species Guazuma ulmifolia in the Palo Verde site in Costa Rica can be attributed to the presence of cattle at that site and that its abundance results in the lowest levels of species richness of the three sites considered in this study, and the lowest rates of their recovery (Supplementary material Appendix 1 Fig.

A1, Appendix 2 Fig. A2). (5) Both types of previous land use can be found in the same landscape (Castellanos-Castro and Newton 2015) enabling seed dispersal between these two types of secondary forest that can result in a homogenization of species composition. (6) The use of fire as a management technique, which was mentioned by some included studies both for shifting cultivation (Kennard 2002, Rico-Gray and Garcia-Franco 1992) and pasture (Leiva et al. 2009, Powers et al. 2009), decreases the ability of trees to resprout and reduces the viability of seeds in the soil seed bank (Hooper et al. 2004, Kennard et al. 2002). Nonetheless, our finding that despite all of these complex interacting factors, there was a faster rate of recovery of species evenness during succession on sites previously under pasture than those used for shifting cultivation does show the potential importance of the legacy effects of past land use. This merits further research focused on factors such as survival of remnant vegetation (Chazdon 2003) and the soil seed bank, and soil condition to improve understanding of the mechanisms and scale of its impact on subsequent secondary succession.

Our results did not show any significant effect of precipitation regime (MAP and number of dry months) or water availability (PET/MAP) on changes in species richness, evenness or composition (Fig. 1, Fig. 2). The effect of precipitation and water availability on species presence and abundance is therefore different than their effect on biomass, whose recovery increases with increasing precipitation and water availability (Becknell et al. 2012, Poorter et al. 2016). A possible explanation of our results is that the gradients in precipitation regime and water availability can have several opposing effects. The greater importance of resprouting (McDonald et al. 2010) and facilitation (Callaway and Walker 1997) can lead to a faster accumulation of species in drier sites but this can be mitigated by the smaller pools of species capable of tolerating drought. Moreover, the influence of precipitation regime and water availability on both species accumulation and changes in species composition can be obscured by the importance of the remnant vegetation for resprouting, facilitation and seed availability and dispersion (Chazdon 2014).

Other factors not included in our analysis could explain the heterogeneity of successional trajectories. (1) The position of successional forests in the landscape relative to old-growth forests is important for the input of seeds (Arroyo-Rodriguez et al. 2016, Chazdon 2014, Sovu et al. 2009). The

'This article is protected by copyright. All rights reserved.' 
direction of the old-growth forests relative to the dominant winds can also affect the species composition of the dispersed seeds (Castillo-Nunez et al. 2011, Janzen 1988). (2) Soil properties: Powers et al. (2009) found that the species composition and the trajectories of changes in diversity differed between three sites with different soils. (3) Stochastic events probably explain part of the heterogeneity between datasets (Norden et al. 2015).

\section{Methodological considerations}

The variation in methodology used by the original studies, in terms of plot size, nested design and minimum stem diameter for inclusion, can partly explain the high heterogeneity between data sets that we observed. However, the potential risk of bias is minimised by the fact that we first calculated an effect size per dataset before combining the datasets in the meta-analyses.

We have chosen to use the slope of linear regressions as a common effect size metric for the meta-analyses as it appeared to be a parsimonious choice (Supplementary material Appendix 1 Fig. A1), although some of these relationships are often non-linear (Newton and Cantarello 2015, Quesada et al. 2009) (Fig. 1, Fig. 2, Supplementary material Appendix 1 Fig. A1). Our results therefore show direction and relative rates of change with succession rather than quantitative predictions of indices at a given age. Despite high heterogeneity between studies, these trends were particularly robust, which allows them to be interpreted as global trends in TDF, while giving consideration to the geographical bias mentioned hereafter.

The majority of the studies that we found were conducted in the Neotropics (and especially in Mexico and Costa Rica) (Table 1), which is also the case for other meta-analysis of succession in tropical forests (Becknell et al. 2012, Martin et al. 2013), reflecting the wider trend of unbalanced distribution of ecological studies in the tropics (Powers et al. 2011, Stocks et al. 2008). Because of this geographical bias, caution is required in extrapolating our results to African and Asian dry forests. More studies on successional forests in these regions are greatly needed to assess how their characteristics, such as the smaller overall species pool in Africa (Slik et al. 2015) and differences in disturbance history and forest fauna (Corlett and Primack 2006), affect their rate of recovery.

All the considered studies are based on chronosequences, reflecting the low number of dynamic studies of tropical forest succession (Chazdon et al. 2007). This space-for-time substitution approach has been criticized for the potential biases related to the difficulty of (1) distinguishing patterns associated with succession from those resulting from variation in initial conditions (Pickett 1989), and (2) accounting for the possible correlation between time of abandonment and site conditions (such as soil

'This article is protected by copyright. All rights reserved.' 
fertility) (Chazdon 2003). However, they are recognized as a useful approach for assessing long-term direction of change (Lebrija-Trejos et al. 2010). Moreover, Mora et al. (2015) showed by combining chronosequence and dynamic approaches, that chronosequence models had greater power for predicting species-based patterns (diversity and composition) than structural patterns. It is important to recognize, however, that there may be a bias in scientists' choice of study sites towards areas where changes with succession are obvious and therefore easier to quantify, potentially leading to an overestimation of the resilience capacity of TDF. A dynamic approach following succession from its earliest stages would be less subject to this bias.

\section{Conclusions}

Meta-analysis of 13 datasets showed directionality and convergence of changes in species richness, evenness and composition of tree and shrub communities with succession. This supports the importance of deterministic processes for successional trajectories in TDF despite large levels of uncertainty (Norden et al. 2015). Our results indicate an overall resilience of TDF species richness, supporting the potential of secondary forests for long-term biodiversity conservation even with on-going periodic severe human disturbance. However, active conservation interventions may still be beneficial because recovery of the species composition of old-growth forests is slow and uncertain, and secondary forests may never reach the same composition as old-growth forests. The high heterogeneity between the datasets reflects the complexity of the interacting factors affecting succession in determining the assembly of secondary forest communities (Chazdon 2003). Succession of TDF is therefore an issue deserving further study. A focus on Asian and African dry forests will be needed to fill the biggest geographical gaps in current evidence. There is also a need for more detailed assessment of the legacy effects of previous land use (Chazdon 2003) and the effect of landscape-scale patterns (Arroyo-Rodriguez et al. 2016).

\section{Acknowledgements}

We thank Sovu and P. Spittler for providing data and Robin Chazdon and Lourens Poorter for extremely valuable comments on an earlier version. GD was supported by the European Commission under the FONASO Erasmus Mundus Joint Doctorate Programme, PB by the project SEP-CONACYT 2009-129740, the Fundación Ecológica de Cuixmala and the RedMexLter, DKK by BOLFOR, ELT by the SNI program of SENACYT Panama and JSP by a National Science Foundation CAREER award DEB-1053237.

'This article is protected by copyright. All rights reserved.' 


\section{References}

Anderson, K. J. 2007. Temporal patterns in rates of community change during succession. - Am. Nat. 169: 780-793.

Arroyo-Rodriguez, V. et al. 2016. Multiple successional pathways in human-modified tropical landscapes: new insights from forest succession, forest fragmentation and landscape ecology research. Biol. Rev. doi: 10.1111/brv.12231.

Becknell, J. M. et al. 2012. Aboveground biomass in mature and secondary seasonally dry tropical forests: a literature review and global synthesis. - Forest Ecol. Manag. 276: 88-95.

Bullock, S. H. 1995. Plant reproduction in neotropical dry forests. - In: Bullock, S. H. et al. (eds.), Seasonally dry tropical forests. Cambridge Univ. Press, pp. 277-303.

Callaway, R. M. and Walker, L. R. 1997. Competition and facilitation: a synthetic approach to interactions in plant communities. - Ecology 78: 1958-1965.

Capers, R. S. et al. 2005. Successional dynamics of woody seedling communities in wet tropical secondary forests. - J. Ecol. 93: 1071-1084.

Castellanos-Castro, C. and Newton, A. C. 2015. Environmental heterogeneity influences successional trajectories in Colombian seasonally dry tropical forests. - Biotropica 47: 660-671.

Castillo-Nunez, M. et al. 2011. Delineation of secondary succession mechanisms for tropical dry forests using LiDAR. - Remote Sens. Environ. 115: 2217-2231.

Chao, A. et al. 2005. A new statistical approach for assessing similarity of species composition with incidence and abundance data. - Ecol. Lett. 8: 148-159.

Chave, J. 2004. Neutral theory and community ecology. - Ecol. Lett. 7: 241-253.

Chazdon, R. and Arroyo, J. P. 2013. Tropical forests as complex adaptive systems. - In: Messier, C. et al. (eds.), Managing forests as complex adaptive systems - building resilience to the challenge of global change. Routledge, pp. 35-59.

'This article is protected by copyright. All rights reserved.' 
Chazdon, R. L. 2003. Tropical forest recovery: legacies of human impact and natural disturbances. Perspect. Plant Ecol. Evol. Syst. 6: 51-71.

Chazdon, R. L. 2008. Beyond deforestation: restoring forests and ecosystem services on degraded lands.

- Science 320: 1458-1460.

Chazdon, R. L. 2014. Second growth - the promise of tropical forest regeneration in an age of deforestation. - Univ. of Chicago Press.

Chazdon, R. L. et al. 2007. Rates of change in tree communities of secondary Neotropical forests following major disturbances. - Philos. T. R. Soc. B 362: 273-289.

Chazdon, R. L. et al. 2011. Seasonally dry tropical forest biodiversity and conservation value in agricultural landscapes of mesoamerica. - In: Dirzo, R. et al. (eds.), Seasonally dry tropical forests: ecology and conservation. Island Press, pp. 195-220.

Clements, F. E. 1916. Plant succession: an analysis of the development of vegetation. - Carnegie Institution of Washington.

Cleveland, W. S. et al. 1992. Local regression models. - In: Chambers, J. M. and Hastie, T. J. (eds.), Statistical Models in S. Wadsworth \& Brooks/CRC, pp. 309-376.

Cochran, W. G. 1954. The combination of estimates from different experiments. - Biometrics 10: 101129.

Colwell, R. K. et al. 2012. Models and estimators linking individual-based and sample-based rarefaction, extrapolation and comparison of assemblages. - J. Plant Ecol. 5: 3-21.

Connell, J. H. 1978. Diversity in tropical rain forests and coral reefs. - Science 199: 1302-1310.

Connell, J. H. and Slatyer, R. O. 1977. Mechanisms of succession in natural communities and their role in community stability and organization. - Am. Nat. 111: 1119-1144.

Corlett, R. T. and Primack, R. B. 2006. Tropical rainforests and the need for cross-continental comparisons. - Ecol. Lett. 21: 104-110.

'This article is protected by copyright. All rights reserved.' 
Dent, D. H. et al. 2013. Secondary forests of central Panama increase in similarity to old-growth forest over time in shade tolerance but not species composition. - J. Veg. Sci. 24: 530-542.

Derroire, G. et al. 2016. Isolated trees as nuclei of regeneration in tropical pastures: testing the importance of niche-based and landscape factors. - J. Veg. Sci. doi: 10.1111/jvs.12404.

Derroire, G. et al. 2016. The effects of established trees on woody regeneration during secondary succession in tropical dry forests. - Biotropica doi: 10.1111/btp.12287.

Duarte, L. d. S. et al. 2010. Testing for the influence of niche and neutral factors on sapling community assembly beneath isolated woody plants in grasslands. - J. Veg. Sci. 21: 462-471.

Egler, F. E. 1954. Vegetation science concepts I. initial floristic composition, a factor in old-field vegetation development. - Vegetatio 4: 412-417.

Ewel, J. J. 1977. Differences between wet and dry successional tropical ecosystems. - Geo-Eco-Trop 1: 103-117.

Finegan, B. 1984. Forest Succession. - Nature 312: 109-114.

Gravel, D. et al. 2006. Reconciling niche and neutrality: the continuum hypothesis. - Ecol. Lett. 9: 399409.

Guevara, S. et al. 1986. The role of remnant forest trees in tropical secondary succession. - Vegetatio 66: 77-84.

Holdridge, L. R. 1967. Life zone ecology. - Tropical Science Center.

Hooper, E. R. et al. 2004. Factors affecting community composition of forest regeneration in deforested, abandoned land in Panama. - Ecology 85: 3313-3326.

Hsieh, T. C. et al. 2015. iNEXT: iNterpolation and EXTrapolation for species diversity. http://chao.stat.nthu.edu.tw/blog/software-download.

Hubbell, S. P. 2001. The unified neutral theory of biodiversity and biogeography. - Princeton Univ. Press.

'This article is protected by copyright. All rights reserved.' 
Huston, M. and Smith, T. 1987. Plant succession : life history and competition. - Am. Nat. 130: 168-198.

Janzen, D. H. 1988. Management of habitat fragments in a tropical dry forest: growth. - Ann. Mo. Bot. Gard. 75: 105-116.

Janzen, D. H. 2002. Tropical dry forest: Area de Conservación Guanacaste, northwestern Costa Rica. - In: Perrow, M. R. and Davy, A. J. (eds.), Handbook of ecological restoration, volume 2, restoration in practice. Cambridge Univ. Press, pp. 559-583.

Jennions, M. D. et al. 2013. Publication and related biases. - In: Koricheva, J. et al. (eds.), Handbook of meta-analysis in ecology and evolution. Princeton Univ. Press, pp. 207-236.

Kassi N'Dja, J. K. and Decocq, G. 2008. Successional patterns of plant species and community diversity in a semi-deciduous tropical forest under shifting cultivation. - J. Veg. Sci. 19: 809-812.

Kennard, D. K. 2002. Secondary forest succession in a tropical dry forest: patterns of development across a 50-year chronosequence in lowland Bolivia. - J. Trop. Ecol. 18: 53-66.

Kennard, D. K. et al. 2002. Effect of disturbance intensity on regeneration mechanisms in a tropical dry forest. - Forest Ecol. Manag. 162: 197-208.

Koricheva, J. and Gurevitch, J. 2013. Place of meta-analysis among other methods of research synthesis. - In: Koricheva, J. et al. (eds.), Handbook of meta-analysis in ecology and evolution. Princeton Univ. Press, pp. 3-13.

Koricheva, J. and Gurevitch, J. 2014. Uses and misuses of meta-analysis in plant ecology. - J. Ecol. 102: 828-844.

Larkin, C. C. et al. 2012. Disturbance type and plant successional communities in bahamian dry forests. Biotropica 44: 10-18.

Lawton, J. H. 1987. Are there assembly rules for successional communities? - In: Gray, A. J. et al. (eds.), Colonization, succession and stability. Blackwell, pp. 225-244.

'This article is protected by copyright. All rights reserved.' 
Lebrija-Trejos, E. et al. 2008. Successional change and resilience of a very dry tropical deciduous forest following shifting agriculture. - Biotropica 40: 422-431.

Lebrija-Trejos, E. et al. 2010. Pathways, mechanisms and predictability of vegetation change during tropical dry forest succession. - Perspect. Plant Ecol. Evol. Syst. 12: 267-275.

Lebrija-Trejos, E. et al. 2011. Environmental changes during secondary succession in a tropical dry forest in Mexico. - J. Trop. Ecol. 27: 477-489.

Leiva, J. A. et al. 2009. Chronology of tropical dry forest regeneration in Santa Rosa, Guanacaste, Costa Rica. II. Vegetation in relation to the soil. - Rev. Biol. Trop. 57: 817-836.

Letcher, S. G. and Chazdon, R. L. 2009. Rapid recovery of biomass, species richness, and species composition in a forest chronosequence in northeastern Costa Rica. - Biotropica 41: 608-617.

Letcher, S. G. et al. 2015. Environmental gradients and the evolution of successional habitat specialization: a test case with 14 Neotropical forest sites. - J. Ecol. 103: 1276-1290.

Light, R. J. and Pillemer, D. B. 1984. Summing up: The science of reviewing research. - Harvard Univ. Press.

Lohbeck, M. et al. 2013. Successional changes in functional composition contrast for dry and wet tropical forest. - Ecology 94: 1211-1216.

Maass, J. M. and Burgos, A. 2011. Water dynamics at the ecosystem level in seasonally dry tropical forests. - In: Dirzo, R. et al. (eds.), Seasonally dry tropical forests: ecology and conservation. Island Press, pp. 141-156.

Maass, J. M. et al. 1988. Soil erosion and nutrient losses in seasonal tropical agroecosystems under various management techniques. - J. Appl. Ecol. 25: 595-607.

Magurran, A. E. 2005. Measuring biological diversity. - Blackwell.

Martin, P. A. et al. 2013. Carbon pools recover more quickly than plant biodiversity in tropical secondary forests. - P. Roy. Soc. B-Biol. Sci 280: 20132236.

'This article is protected by copyright. All rights reserved.' 
Maza-Villalobos, S. et al. 2011. Successional trends in soil seed banks of abandoned pastures of a Neotropical dry region. - J. Trop. Ecol. 27: 35-49.

McDonald, M. A. et al. 2010. What are the mechanisms of regeneration post-disturbance in tropical dry forest? - Environ. Evid.: 37.

McIntosh, R. P. 1999. The succession of succession: a lexical chronology. - Bull. Ecol. Soc. Am. 80: 256265.

Mengersen, K. et al. 2013. Statistical models and approaches to inference. - In: Koricheva, J. et al. (eds.), Handbook of meta-analysis in ecology and evolution. Princeton Univ. Press, pp. 89-107.

Molina Colon, S. and Lugo, A. E. 2006. Recovery of a subtropical dry forest after abandonment of different land uses. - Biotropica 38: 354-364.

Mora, F. et al. 2015. Testing chronosequences through dynamic approaches: time and site effects on tropical dry forest succession. - Biotropica 47: 38-48.

Morales-Barquero, L. et al. 2015. Identification and quantification of drivers of forest degradation in tropical dry forests: a case study in Western Mexico. - Land Use Policy 49: 296-309.

Newton, A. C. and Cantarello, E. 2015. Restoration of forest resilience: An achievable goal? - New For. 46: 645-668.

Norden, N. et al. 2009. Resilience of tropical rain forests: tree community reassembly in secondary forests. - Ecol. Lett. 12: 385-394.

Norden, N. et al. 2015. Successional dynamics in Neotropical forests are as uncertain as they are predictable. - P. Natl. Acad. Sci. USA 112: 8013-8018.

Oksanen, J. et al. 2015. vegan: Community Ecology Package. - http://CRAN.Rproject.org/package=vegan .

Pereira, I. M. et al. 2003. Use-history effects on structure and flora of Caatinga. - Biotropica 35: 154-165.

'This article is protected by copyright. All rights reserved.' 
Pickett, S. A. 1989. Space-for-time substitution as an alternative to long-term studies. - In: Likens, G. (ed.) Long-Term Studies in Ecology. Springer pp. 110-135.

Poorter, L. et al. 2016. Biomass resilience of Neotropical secondary forests. - Nature doi: $10.1038 /$ nature16512.

Powers, J. S. et al. 2009. Diversity and structure of regenerating tropical dry forests in Costa Rica: Geographic patterns and environmental drivers. - Forest Ecol. Manag. 258: 959-970.

Powers, J. S. et al. 2011. Geographic bias of field observations of soil carbon stocks with tropical land-use changes precludes spatial extrapolation. - P. Natl. Acad. Sci. USA 108: 6318-6322.

Quesada, M. et al. 2009. Succession and management of tropical dry forests in the Americas: review and new perspectives. - Forest Ecol. Manag. 258: 1014-1024.

R core team. 2015. R: A language and environment for statistical computing. -R Foundation for Statistical Computing. R Foundation for Statistical Computing. - https://www.R-project.org/.

Rico-Gray, V. and Garcia-Franco, J. G. 1992. Vegetation and soil seed bank of successional stages in tropical lowland deciduous forest. - J. Veg. Sci. 3: 617-624.

Rosenberg, M. S. 2005. The file-drawer problem revisited: A general weighted method for calculating fail-safe numbers in meta-analysis. - Evolution 59: 464-468.

Rosenberg, M. S. et al. 2013. Effect sizes: conventional choices and calculations. - In: Koricheva, J. et al. (eds.), Handbook of meta-analysis in ecology and evolution. Princeton Univ. Press, pp. 61-71.

Rosenthal, R. 1979. The "file drawer problem" and tolerance for null results. - Psychol. Bull. 86: 638-641.

Rozendaal, D. M. A. and Chazdon, R. L. 2015. Demographic drivers of tree biomass change during secondary succession in northeastern Costa Rica. - Ecol. Appl. 25: 506-516.

Ruiz, J. et al. 2005. Vegetation structure, composition, and species richness across a 56-year chronosequence of dry tropical forest on Providencia island, Colombia. - Biotropica 37: 520-530.

'This article is protected by copyright. All rights reserved.' 
Saldarriaga, J. G. et al. 1988. Long-term chronosequence of forest succession in the upper Rio Negro of Colombia and Venezuela. - J. Ecol. 76: 938-958.

Sampaio, A. B. 2007. Regeneration of seasonal deciduous forest tree species in long-used pastures in central Brazil. - Biotropica 39: 655-659.

Sanchez-Azofeifa, G. A. et al. 2005. Research priorities for neotropical dry forests. - Biotropica 37: 477485.

Sandor, M. E. and Chazdon, R. L. 2014. Remnant trees affect species composition but not structure of tropical second-growth forest. - PLoS ONE 9: e83284.

Schlawin, J. and Zahawi, R. A. 2008. 'Nucleating' succession in recovering neotropical wet forests: The legacy of remnant trees. - J. Veg. Sci. 19: 485-U487.

Slik, J. W. F. et al. 2015. An estimate of the number of tropical tree species. - P. Natl. Acad. Sci. USA 112: 7472-7477.

Souza, F. M. and Batista, J. L. F. 2004. Restoration of seasonal semideciduous forests in Brazil: influence of age and restoration design on forest structure. - Forest Ecol. Manag. 191: 185-200.

Sovu et al. 2009. Recovery of secondary forests on swidden cultivation fallows in Laos. - Forest Ecol. Manag. 258: 2666-2675.

Spittler, P. 2001. Potencial de manejo de los bosques secundarios en la zona seca del noroeste de Costa Rica. - GTZ.

Stocks, G. et al. 2008. The geographical and institutional distribution of ecological research in the tropics. - Biotropica 40: 397-404.

Tilman, D. 2004. Niche tradeoffs, neutrality, and community structure: A stochastic theory of resource competition, invasion, and community assembly. - P. Natl. Acad. Sci. USA 101: 10854-10861.

Viechtbauer, W. 2010. Conducting meta-analyses in R with the metafor package. - J. Stat. Softw. 36: 148. 
Vieira, D. L. M. and Scariot, A. 2006. Principles of natural regeneration of tropical dry forests for restoration. - Restor. Ecol. 14: 11-20.

Vieira, D. L. M. et al. 2006. Tropical dry-forest regeneration from root suckers in Central Brazil. - J. Trop. Ecol. 22: 353-357.

Woodcock, P. et al. 2014. Evaluating and improving the reliability of evidence syntheses in conservation and environmental science: A methodology. - Biol. Conserv. 176: 54-62.

Young, T. P. et al. 2005. The ecology of restoration: historical links, emerging issues and unexplored realms. - Ecol. Lett. 8: 662-673.

Supplementary material (Appendix oik.XXXXX at www.oikosjournal.org/readers/appendix). Appendix 1-6. 


\section{Table Legend}

Table 1. Datasets included in the meta-analyses of successional tropical dry forests. Shifting means shifting cultivation, MAP is the mean annual precipitation, PET is the annual potential evapotranspiration. The threshold for a dry month is $<100 \mathrm{~mm}$ of monthly precipitation. The crosses in the last four columns indicate which meta-analyses each dataset was included in. For datasets using a nested design, the plot area is the largest one used in the dataset. The number of plots refers to successional plots only (it excludes old-growth forest plots). This information refers to the data used in the meta-analysis, after data preparation, and can therefore differ slightly from those reported in the original publications.

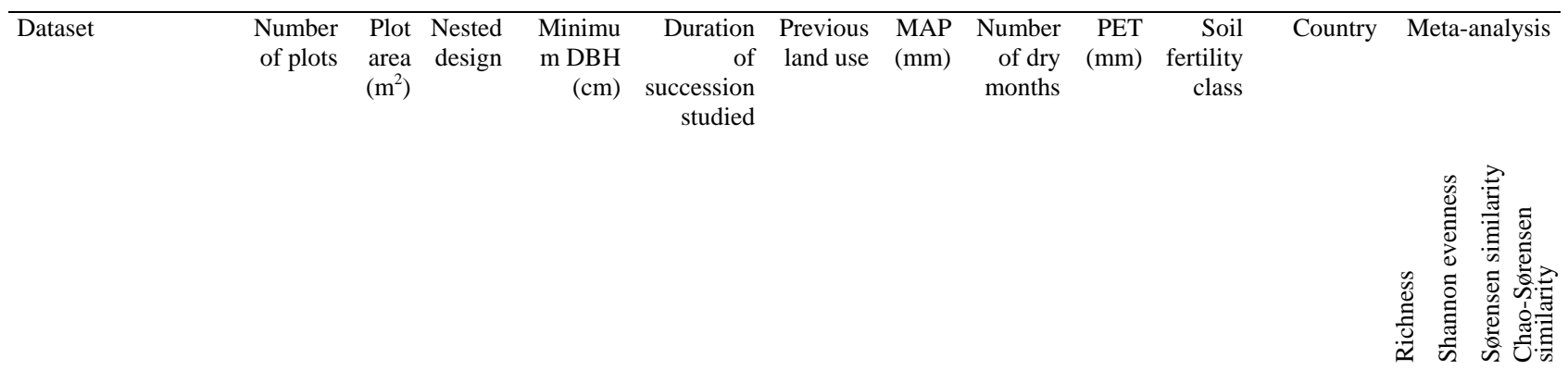

\begin{tabular}{|c|c|c|c|c|c|c|c|c|c|c|c|c|c|c|c|}
\hline $\begin{array}{l}\text { Castellanos-Castro } \\
\text { and Newton (2015) }\end{array}$ & 21 & 100 & no & 2.5 & $7-27.5$ & pasture & 900 & 5 & 1573 & high & Colombia & $\mathrm{X}$ & $\mathrm{X}$ & & \\
\hline $\begin{array}{l}\text { - Ceibal - pasture } \\
\text { Castellanos-Castro } \\
\text { and Newton (2015) } \\
\text { - Rosales - pasture }\end{array}$ & 8 & 100 & no & 2.5 & $3.5-20$ & pasture & 900 & 5 & 1573 & high & Colombia & $\mathrm{X}$ & $\mathrm{X}$ & & \\
\hline $\begin{array}{l}\text { Castellanos-Castro } \\
\text { and Newton (2015) } \\
\text { - Rosales - shifting }\end{array}$ & 10 & 100 & no & 2.5 & $3.5-15$ & shifting & 900 & 5 & 1573 & high & Colombia & $\mathrm{X}$ & $\mathrm{X}$ & & \\
\hline Kennard (2002) & 60 & 1000 & yes & 5 & $5-50$ & shifting & 1129 & 6 & 1701 & high & Bolivia & $\mathrm{X}$ & $\mathrm{X}$ & & \\
\hline $\begin{array}{l}\text { Lebrija-Trejos et al. } \\
(2008)\end{array}$ & 14 & 400 & yes & 1 & $3-60$ & shifting & 900 & 7.5 & 1799 & high & Mexico & $\mathrm{X}$ & $\mathrm{X}$ & $\mathrm{X}$ & $\mathrm{X}$ \\
\hline Leiva et al. (2009) & 100 & 500 & no & 5 & $10-60$ & pasture & 1575 & 5.5 & 1426 & high & Costa Rica & $\mathrm{X}$ & $\mathrm{X}$ & $\mathrm{X}$ & $\mathrm{X}$ \\
\hline Mora et al. (2015) & 8 & 500 & no & 2.5 & $1-10$ & pasture & 788 & 7 & 1510 & no data & Mexico & $\mathrm{X}$ & $\mathrm{X}$ & $\mathrm{X}$ & $\mathrm{X}$ \\
\hline $\begin{array}{l}\text {-owers et al. (2009) } \\
\text { - Palo Verde TDF }\end{array}$ & 19 & 1000 & no & 10 & $7-60$ & pasture & 1492 & 5 & 1484 & high & Costa Rica & $X$ & $\mathrm{X}$ & & \\
\hline $\begin{array}{l}\text { Powers et al. (2009) } \\
\text { - Santa Rosa oak }\end{array}$ & 16 & 1000 & no & 10 & $5-30$ & pasture & 1575 & 5.5 & 1453 & low & Costa Rica & $\mathrm{X}$ & $\mathrm{X}$ & & \\
\hline $\begin{array}{l}\text { Powers et al. (2009) } \\
\text { - Santa Rosa TDF }\end{array}$ & 22 & 1000 & no & 10 & $6-60$ & pasture & 1575 & 5.5 & 1453 & high & Costa Rica & $\mathrm{X}$ & $\mathrm{X}$ & $\mathrm{X}$ & $\mathrm{X}$ \\
\hline $\begin{array}{l}\text { Rico-Gray and } \\
\text { Garcia-Franco } \\
\text { (1992) }\end{array}$ & 4 & 1000 & no & 1 & $10-40$ & shifting & 950 & 7 & 1594 & high & Mexico & $\mathrm{X}$ & $\mathrm{X}$ & $\mathrm{X}$ & $\mathrm{X}$ \\
\hline Sovu et al. (2009) & 290 & 100 & no & 1 & $1-19$ & shifting & 1647 & 6 & 1368 & high & Laos & $\mathrm{X}$ & $\mathrm{X}$ & & \\
\hline Spittler (2001) & 257 & 154 & no & 5 & $6-50$ & pasture & 1575 & 5.5 & 1469 & high & Costa Rica & $\mathrm{X}$ & $\mathrm{X}$ & $\mathrm{X}$ & $\mathrm{X}$ \\
\hline
\end{tabular}

'This article is protected by copyright. All rights reserved.' 


\section{Figure Legends}

Figure 1. Estimated effect sizes (slope of the linear regression against successional age) of one metaanalysis (all datasets) and two meta-regressions (with previous land use and duration of succession studied) for a) species richness (standardized to 15 individuals) and b) Shannon evenness index, from meta-analysis of tropical dry forest datasets. The error bars indicate $95 \%$ confidence intervals. The estimate of effect size is significant if the confidence interval excludes $0 . \mathrm{N}$ is the number of datasets for each case. Nfs is the fail-safe number for the significant effect size: it assesses the number of datasets with a null estimate that would need to be added to make the result non-significant. The estimate is robust if $\mathrm{Nfs}>5 \mathrm{~N}+10$ (indicated with an asterix). $\mathrm{p}_{\text {diff }}$ is the $\mathrm{p}$-value for the significance of the difference between two modalities of a moderator. Heterogeneity between datasets is tested with Cochran's Q test for metaanalysis without moderators and with the Q-E test for meta-regression with moderators, a significant pvalue indicates heterogeneity. Shifting means shifting cultivation.

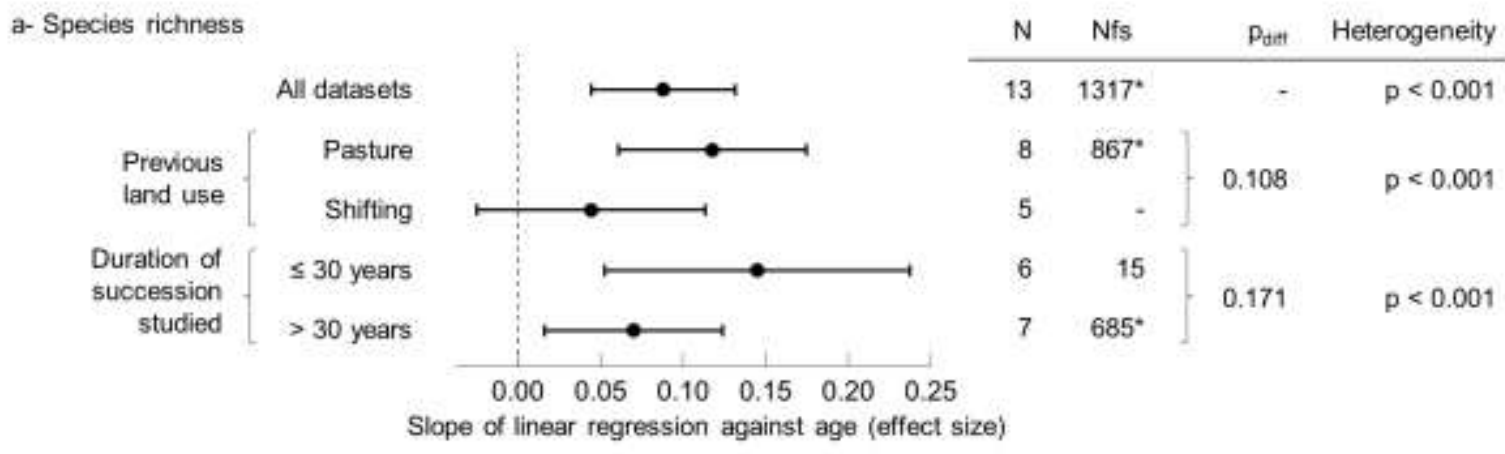

b- Shannon evenness index

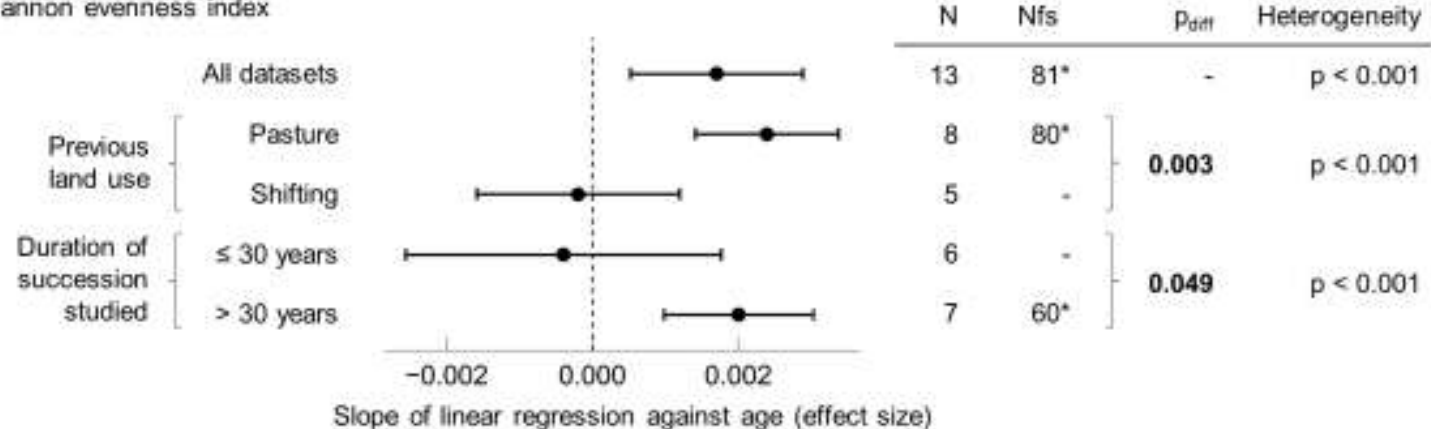

Slope of linear regression against age (effect size)

'This article is protected by copyright. All rights reserved.' 
Figure 2. Estimated effect size (slope of the linear regression against successional age) of one metaanalysis (all datasets) and two meta-regressions (with previous land use and duration of succession studied) for a) the Sørensen and b) the Chao-Sørensen species composition similarity indices for trees and shrubs, from meta-analysis of tropical dry forest datasets. The error bars indicate $95 \%$ confidence intervals. The estimate of the effect size is significant if the confidence interval excludes $0 . \mathrm{N}$ is the number of datasets for each case. Nfs is the fail-safe number for the significant effect size: it assesses the number of datasets with a null estimate that would need to be added to make the result non-significant. The estimate is robust if $\mathrm{Nfs}>5 \mathrm{~N}+10$ (indicated with an asterix). $\mathrm{p}_{\text {diff }}$ is the $\mathrm{p}$-value for the significance of the difference between two modalities of a moderator. Heterogeneity between datasets is tested with Cochran's Q test for meta-analysis without moderators and with the Q-E test for meta-regression with moderators, a significant p-value indicates heterogeneity. Shifting means shifting cultivation.

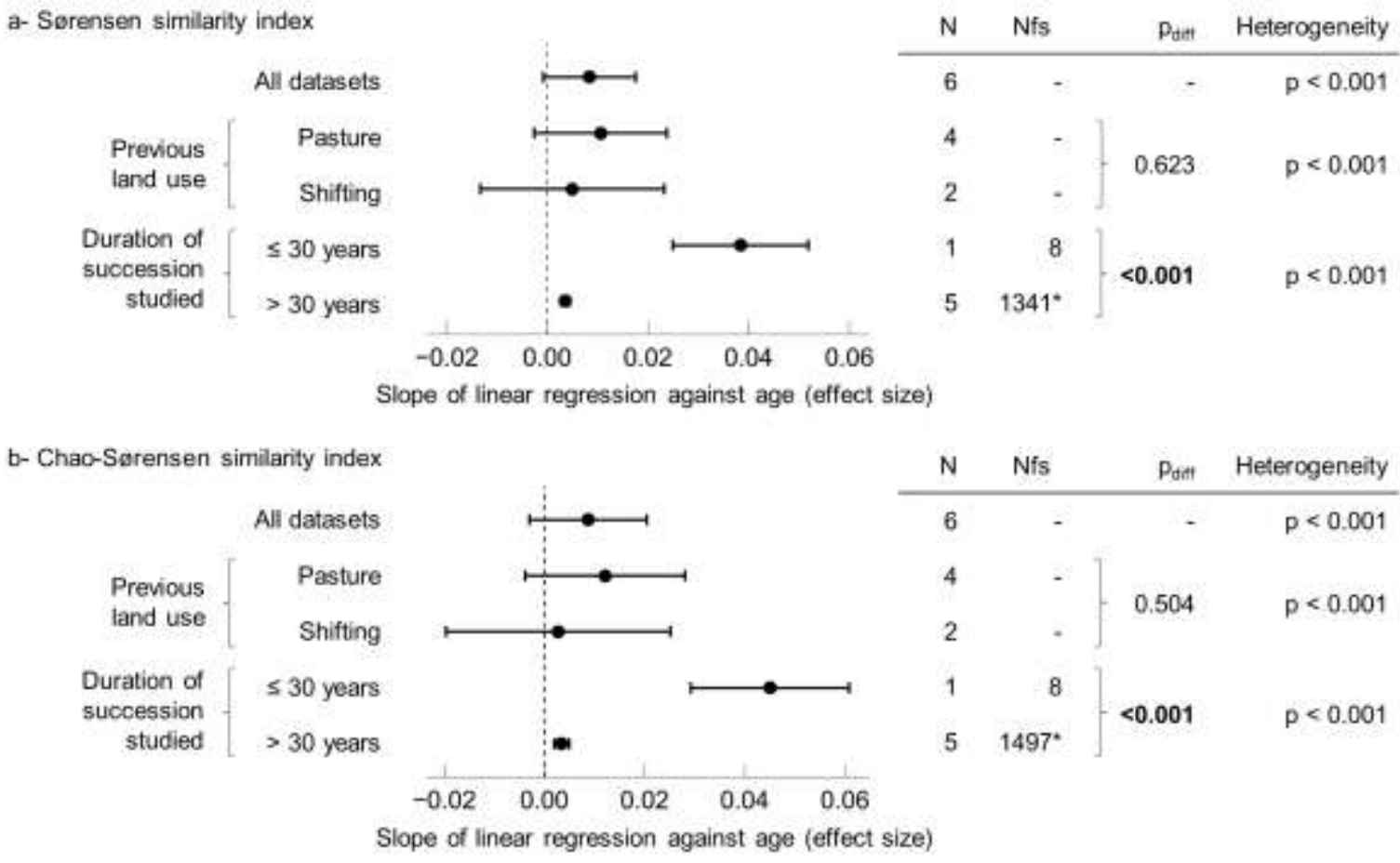

'This article is protected by copyright. All rights reserved.' 